\title{
ZnO Doped With Transition Metal Ions
}

\author{
Stephen J. Pearton, Fellow, IEEE, David P. Norton, Matt P. Ivill, Art F. Hebard, \\ John M. Zavada, Weimin M. Chen, and Irina A. Buyanova
}

\begin{abstract}
Spin-dependent phenomena in $\mathrm{ZnO}$ may lead to devices with new or enhanced functionality, such as polarized solidstate light sources and sensitive biological and chemical sensors. In this paper, we review the experimental results on transition metal doping of $\mathrm{ZnO}$ and show that the material can be made with a single phase at high levels of Co incorporation ( $\sim 15$ at.\%) and exhibits the anomalous Hall effect. $\mathrm{ZnO}$ is expected to be one of the most promising materials for room-temperature polarized light emission; but to date, we have been unable to detect the optical spin polarization in $\mathrm{ZnO}$. The short spin relaxation time observed likely results from the Rashba effect. Possible solutions involve either cubic phase $\mathrm{ZnO}$ or the use of additional stressor layers to create a larger spin splitting in order to get a polarized light emission from these structures or to look at alternative semiconductors and fresh device approaches.
\end{abstract}

Index Terms-Spintronics, $\mathrm{ZnO}$.

\section{INTRODUCTION}

$\mathbf{T}$ HERE IS current interest in the development of dilute magnetic semiconductors (DMS) exhibiting ferromagnetic behavior for spin-based light-emitting diodes, sensors, and transistors [1]-[3]. These materials are formed through the introduction of transition metal (TM) ions, such as $\mathrm{Mn}$ and $\mathrm{Cr}$, or rare earth ions into the host semiconductor. Both types of ions have partially filled $d$ and $f$ shells, respectively, which give rise to unpaired electrons. The magnetic behavior of such materials depends upon the concentration of the TM ions in the crystal, the carrier density, and the crystal quality. The term DMS refers to the fact that some fractions of the atoms in a nonmagnetic semiconductor host like $\mathrm{ZnO}$ are replaced by magnetic ions. Generally, when $3 d$ TM ions are substituted for the cations of the host, their electronic structure is influenced by the strong $3 d$ orbitals of the magnetic ion and the $p$ orbitals of the neighboring anions. There are two interacting subsystems in DMS materials, namely the delocalized conduction

Manuscript received April 11, 2006; revised September 19, 2006. This work was supported in part by the AFOSR grant under Grant F4962003-1-0370, by the Army Research Office under Grant DAAD19-01-1-0603, and by the National Science Foundation (DMR 0400416, Dr. L. Hess). The review of this paper was arranged by Editor R. Ramesh.

S. J. Pearton, D. P. Norton, and M. P. Ivill are with the Department of Materials Science and Engineering, University of Florida, Gainesville, FL 32611 USA (e-mail: spear@mse.ufl.edu).

A. F. Hebard is with the Department of Physics, University of Florida, Gainesville, FL 32611 USA.

J. M. Zavada is with the Army Research Office, Research Triangle Park, NC 27709 USA.

W. M. Chen and I. A. Buyanova are with the Department of Physics and Measurement Technology, Linköping University, 58183 Linköping, Sweden.

Color versions of one or more of the figures in this paper are available online at http://ieeexplore.iee.org.

Digital Object Identifier 10.1109/TED.2007.894371

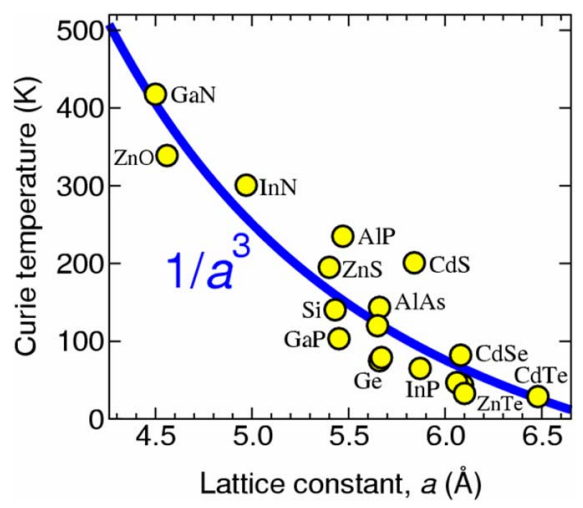

Fig. 1. Predicted Curie temperature as a function of lattice constant for a variety of semiconductors [after S.C.Erwin (Naval Research Laboratory)]. The materials predicted to have high $T_{C}$ s have large $p-d$ hybridization and small spin-orbit interaction.

band electrons and valence band holes and the random diluted system of localized magnetic moments associated with the magnetic atoms.

The discovery of ferromagnetic ordering in the Mn-doped narrow bandgap semiconductors generated a tremendous attention. However, DMS materials such as GaMnAs, InMnAs, and $\mathrm{GaMnSb}$, have thus far shown a relatively low magnetic ordering temperature $(\sim 170 \mathrm{~K}$ for GaMnAs), which limits their utility. Recently, many research groups have reported a work directed toward achieving ferromagnetism at or above room temperature in wide bandgap materials, such as $\mathrm{GaMnN}$ and $\mathrm{ZnMnO}$ [4]-[70]. This property makes these materials attractive for use as nonvolatile switching elements, where the bit state of the device is determined through the control of electron spin. In addition, the integration of photonic (laser and light-emitting diodes), electronic (field-effect and bipolar transistors), and magnetic (information storage) devices on a single substrate, leading to a new class of electronic devices that offer multipurpose functionality, might be possible with the availability of the DMS materials with high Curie temperatures. Fig. 1 shows that the wider bandgap semiconductors, which tend to have smaller lattice constants, large $p-d$ hybridization, and small spin-orbit interaction, are predicted to have higher Curie temperatures [10].

\section{Mechanisms For Ferromagnetism}

Mean field theory predicts that the Curie temperature for high carrier density DMS materials such as GaMnAs will be given by [1]-[3], [10]

$$
T_{C}=C N_{\mathrm{Mn}} \beta^{2} m^{*} p^{1 / 3}
$$


where $N_{\mathrm{Mn}}$ is the concentration of uncompensated Mn spins, $\beta$ is the coupling constant between the localized Mn spins and the free holes ( $p-d$ coupling), $m^{*}$ is the effective mass of the holes, and $p$ is the free hole concentration. It is now generally accepted that for low carrier density systems such as $\mathrm{ZnO}$, mechanisms other than the carrier-induced ferromagnetism are more likely, such as the formation of bound magnetic polarons in a system that also has direct antiferromagnetic coupling between closely spaced TM ions [5]. As the sample temperature is lowered, the polarons increase in radius and eventually overlap at the Curie temperature.

Much of the theory for $\mathrm{ZnO}$ DMS materials has come from Sato and Katayama-Yoshida [5], [11], [30]-[33]. The ferromagnetic state is predicted to stabilize for most of the TM dopants except Mn. For $\mathrm{ZnO}$, some of the theoretical predictions suggest that only $p$-type (Zn, Mn)O can lead to ferromagnetism. However, most of the experimental observations of ferromagnetism have been for insulating $(\mathrm{Zn}, \mathrm{Mn}) \mathrm{O}, n$-type $(\mathrm{Zn}, \mathrm{Mn}) \mathrm{O}$, and undoped $(\mathrm{Zn}, \mathrm{Mn}) \mathrm{O}$. Values of $T_{C}$ above room temperature have been reported for $\mathrm{Mn}, \mathrm{Co}, \mathrm{Sc}, \mathrm{Ti}$, and $\mathrm{V}$-doped $n$-type $\mathrm{ZnO}$ powders and films deposited on variety of substrates (usually sapphire) by a variety of methods, including sintering and pulsed laser deposition (PLD). Table I shows a compilation of recent work in this area [6]-[8].

The most recent model is that due to Coey et al. [4], the so-called spin-split-orbit model. This is consistent with the observed magnetization in $n$-type $\mathrm{ZnO}$ doped with TMs. The ferromagnetic exchange is mediated by shallow donor electrons that form the bound magnetic polarons, which in turn overlap to create a spin-split impurity band. Magnetic ions in different charge states couple by virtual hopping of the "extra" electron from one ion to the other [4]. The $3 d$ electrons in the partially occupied $3 d$ orbitals are allowed to hop to the $3 d$ orbitals of the neighboring TM, if the neighboring TM ions have parallel magnetic moments. The ferromagnetic exchange is mediated by charge carriers in a spin-split impurity band formed by extended donor states. The impurity states hybridize with the $d$-orbits of the TM elements. It was shown that for $\mathrm{Sc}, \mathrm{Ti}$, and $\mathrm{V}$, the spin-up states of the $3 d \mathrm{TM}$ element are aligned with the impurity levels, resulting in significant alignment. Similarly, for $\mathrm{Fe}, \mathrm{Co}$, and $\mathrm{Ni}$ doping, the spin-down states perform the same function. It was suggested that $\mathrm{Mn}$ and $\mathrm{Cr}$ doping would not lead to strong magnetization due to a small hybridization [4], [46], [47], although other reports suggest otherwise.

To be considered a true DMS, it is necessary to show that the carrier population is polarized. This can be done through transport measurements, especially the observation of the anomalous Hall effect (AHE) or by observation of the polarized light emission from a quantum well using the DMS material as a spin injector. The latter has not yet been demonstrated for the $\mathrm{ZnO}$ system. The AHE is a ferromagnetic response of charge carriers in electrically conductive ferromagnets, producing a Hall voltage proportional to the magnetization. Its presence is generally attributed to asymmetric carrier scattering by magnetic impurities in the presence of spin-orbit interactions [28], [65].

The AHE represents the ferromagnetic spin polarization of the charge carriers. Thus, the observation of the AHE was recognized as a strong evidence for the intrinsic ferromag- netism of DMS. However, the AHE can be observed for nonmagnetic material embedded with magnetic clusters when their density is around the bulk percolation threshold [66]. The nonmagnetic material embedded with the magnetic clusters may show an appreciable magnetoresistance in accordance with the saturation of the magnetization, implying the spin-dependent scattering of the charge carriers between the magnetic clusters. Thus, even the presence of the AHE is not a complete proof for the existence of a true DMS material [66].

Ando and coworkers [20], [27] reported the magnetooptical effects in TM-doped $\mathrm{ZnO}$ thin films by a magnetic circular dichroism (MCD). Magnetization measurements showed that some of the films were paramagnetic, and others were ferromagnetic. The MCD clarified that $\mathrm{ZnO}: \mathrm{Co}$ and $\mathrm{ZnO}: \mathrm{Ni}$ were paramagnetic diluted magnetic semiconductors. Ferromagnetic precipitations appear to be responsible for the observed ferromagnetic behaviors. The MCD method measures the optical transitions allowed under various optical polarizations involving split-off bands due to the Zeeman effect, which is enhanced by $s p-d$ exchange interactions. $\mathrm{ZnO}$ films grown on latticematched $\mathrm{ScAlMgO}_{4}$ substrates exhibited an MCD structure at the bandgap of $3.4 \mathrm{eV}$. The MCD spectra of the $\mathrm{ZnO}$ films doped with $\mathrm{Sc}, \mathrm{Ti}, \mathrm{V}, \mathrm{Cr}, \mathrm{Mn}, \mathrm{Co}, \mathrm{Ni}$, and $\mathrm{Cu}$ using a PLD were measured. Those doped with $\mathrm{Mn}, \mathrm{Fe}, \mathrm{Co}, \mathrm{Ni}$, and $\mathrm{Cu}$ showed clear MCD structures near $3.4 \mathrm{eV}$. The films doped with Sc, $\mathrm{Ti}, \mathrm{V}$, and $\mathrm{Cr}$ did not exhibit any magnetooptical effect. The magnetic field and temperature dependence of the MCD spectra show that all of these latter films were paramagnetic. It is also clear from these data that factors such as the crystalline quality can influence the magnetic properties of the DMS materials, and this is certainly true of $\mathrm{ZnO}$ [22], [67].

\section{EXPERIMENTAL RESULTS FOR ZnO DMS}

Table I shows that there is still a wide variation reported for the magnetic properties of the TM-doped $\mathrm{ZnO}$ [6]-[8], [67]. For example, a ferromagnetism with $T_{C}>300 \mathrm{~K}$ was observed in $\mathrm{Zn}_{1-x}\left(\mathrm{Co}_{0.5} \mathrm{Fe}_{0.5}\right)_{x} \mathrm{O}$ thin films prepared by magnetron cosputtering and postannealed in vacuum. However, bulk $\mathrm{Zn}_{1-x} \mathrm{Co}_{x} \mathrm{O}$ has been found to be antiferromagnetic in polycrystalline powder samples prepared by both solid-state and liquid-phase reactions. This antiferromagnetic behavior may result from Co clusters observed in the $\mathrm{Zn}_{1-x} \mathrm{Co}_{x} \mathrm{O}$ powder, together with a population of interstitial Co atoms instead of substitutionl Co [67]. Some experimental data show that homogeneous films of $\mathrm{Zn}_{1-x} \mathrm{Co}_{x} \mathrm{O}$ exhibit a spin-glass behavior, whereas inhomogeneous $\mathrm{Zn}_{1-x} \mathrm{Co}_{x} \mathrm{O}$ films are more likely to demonstrate room-temperature ferromagnetism [6]-[8], [67]. This is an evidence that the Co clusters might be the source of the high $T_{C}$ ferromagnetism in some $\mathrm{Zn}_{1-x} \mathrm{Co}_{x} \mathrm{O}$. Norton et al. observed such an effect for $\mathrm{ZnO}$ films implanted with high doses of Co ions [55]. Given that the concentrations of TM ions needed to achieve high Curie temperatures are at or above the solid solubility, it is clear that small variations in the growth parameters will lead to a variety of outcomes, ranging from uniform alloys to clustering of TM atoms to the precipitation and formation of second phases that may contribute to the observed magnetic properties. 
TABLE I

List of ZnO-BASED DMS RECENTLY REPORTEd (AFTER [8] AND [9])

\begin{tabular}{|c|c|c|c|c|c|c|c|c|c|}
\hline Compound & $\begin{array}{l}\text { TM } \\
\text { content }\end{array}$ & Substrate & $\begin{array}{l}\text { Fabrication } \\
\text { method }\end{array}$ & $\begin{array}{l}\text { Growth } \\
\text { temperature } \\
\left({ }^{\circ} \mathrm{C}\right)\end{array}$ & $\begin{array}{l}\text { Oxygen } \\
\text { pressure } \\
\text { (Torr) }\end{array}$ & $\begin{array}{l}\text { Post- } \\
\text { annealing }\end{array}$ & $\begin{array}{l}T_{c} \\
(\mathbf{K})\end{array}$ & Notes & Reference \\
\hline $\mathrm{ZnO}: \mathrm{Mn}$ & $<0.35$ & $c$-Sapphire & PLD & 600 & $5 \times 10^{-5}$ & & N/A & & 13 \\
\hline $\mathrm{ZnO}: \mathrm{Mn}$ & 0.36 & $c$-Sapphire & PLD & 600 & $5 \times 10^{-5}$ & & N/A & Spin-glass & 12 \\
\hline $\mathrm{Zn}_{1-\mathrm{x}} \mathrm{TM}_{\mathrm{x}} \mathrm{O}$ & & $c$-Sapphire & PLD & $500-600$ & $\begin{array}{l}1 \times 10^{-9} \text { to } \\
10^{-6}\end{array}$ & & $\mathrm{~N} / \mathrm{A}$ & & 14 \\
\hline $\mathrm{ZnO}: \mathrm{Co}$ & $0.02-0.5$ & $c$-Sapphire & PLD & $300-700$ & $\begin{array}{l}1 \times 10^{-6} \text { to } \\
10^{-1}\end{array}$ & & & Spin-glass & 15 \\
\hline $\mathrm{ZnO}: \mathrm{Mn}$ & $0.01-0.36$ & $c$-Sapphire & PLD & 610 & $5 \times 10^{-5}$ & & & Paramagnetic & 18 \\
\hline $\mathrm{ZnO}: \mathrm{Mn}$ & 0.07 & a-sapphire & sputtering & 400 & 0.06 & & & Paramagnetic & 18 \\
\hline $\mathrm{ZnO}: \mathrm{Mn}$ & $0.03-0.2$ & $\operatorname{GaAs}(100)$ & sputtering & $500-600$ & $8 \times 10^{-4}$ & & & & 23 \\
\hline $\begin{array}{l}\mathrm{ZnO}:(\mathrm{Co}, \mathrm{Mn}, \\
\mathrm{Cr} \text {, or } \mathrm{Ni})\end{array}$ & $0.05-0.25$ & $r$-Sapphire & PLD & $350-600$ & $2-4 \times 10^{-5}$ & & $\begin{array}{l}280- \\
300\end{array}$ & $2 \mu_{\mathrm{B}} / \mathrm{Co}$ & 26 \\
\hline $\mathrm{ZnO}: \mathrm{Ni}$ & $0.01-0.25$ & $c$-Sapphire & PLD & $300-700$ & $1 \times 10^{-5}$ & & & $\begin{array}{l}\text { Superpara- or ferro- } \\
\text { magnetic }\end{array}$ & 53 \\
\hline $\mathrm{ZnO}: \mathrm{V}$ & $0.05-0.15$ & $r$-Sapphire & PLD & 300 & $10^{-5}$ to $10^{-3}$ & & $>350$ & $0.5 \mu_{\mathrm{B}} / \mathrm{V}$ & 54 \\
\hline $\mathrm{ZnO}:(\mathrm{Co}, \mathrm{Fe})$ & $<0.15$ & $\mathrm{SiO}_{2} / \mathrm{Si}$ & $\begin{array}{l}\text { Magnetron } \\
\text { sputtering }\end{array}$ & 600 & $2 \times 10^{-3}$ & $\begin{array}{l}600^{\circ} \mathrm{C}, 10 \mathrm{~min}, \\
1.0 \times 10^{-5} \text { Ton }\end{array}$ & $>300$ & $12-15 \mathrm{emu} / \mathrm{cm}^{3}$ & 28 \\
\hline $\mathrm{ZnO}: \mathrm{Co}$ & $0.03-0.05$ & Bulk ZnO & $\begin{array}{l}\text { Ion } \\
\text { implantation }\end{array}$ & & & $\begin{array}{l}700 \mathrm{C}, 5 \mathrm{~min} \\
\text { under } \mathrm{O}_{2}\end{array}$ & $>300$ & $\begin{array}{l}\text { Oriented Co } \\
\text { precipitates }\end{array}$ & 55 \\
\hline $\mathrm{ZnO}: \mathrm{Co}$ & $0-0.25$ & $c$-Sapphire & Sol-gel & $<350$ & & $700^{\circ} \mathrm{C}, 1 \mathrm{~min}$ & $>350$ & $0.56 \mu_{\mathrm{B}} / \mathrm{Co}$ & 57 \\
\hline $\mathrm{ZnO}: \mathrm{Mn}$ & $0-0.3$ & $c$-Sapphire & PLD & & & & $\begin{array}{l}>30- \\
45\end{array}$ & $0.15-0.17 \mu \mathrm{B} / \mathrm{Mn}$ & 21 \\
\hline $\mathrm{ZnO}: \mathrm{Mn}$ & $<0.04$ & & $\begin{array}{l}\text { Sintered } \\
\text { pellets }\end{array}$ & $500-700 \mathrm{C}$ & $\begin{array}{l}\text { Air, } \\
\text { atmospheric } \\
\text { pressure }\end{array}$ & & $>425$ & $\begin{array}{l}0.006 \mathrm{emu} / \mathrm{gm}, \text { single } \\
\text { phase }\end{array}$ & 34 \\
\hline $\mathrm{ZnO}: \mathrm{Mn}$ & 0.02 & $\begin{array}{l}\text { Fused } \\
\text { quartz }\end{array}$ & PLD & $400 \mathrm{C}$ & & & $>425$ & $\begin{array}{l}0.05 \mathrm{emu} / \mathrm{gm}, \text { single } \\
\text { phase }\end{array}$ & 34,35 \\
\hline $\mathrm{ZnO}:(\mathrm{Fe}, \mathrm{Cu})$ & $0-0.1$ & $\begin{array}{l}\text { Solid state } \\
\text { reaction }\end{array}$ & 897 & & & & 550 & $0.75 \mu_{\mathrm{B}} / \mathrm{Fe}$ & 48 \\
\hline $\mathrm{ZnO}: \mathrm{Co}$ & 0.015 & & PLD & $650 \mathrm{C}$ & $5 \times 10^{-5}$ & & $>300$ & ferromagnetic & 58 \\
\hline $\mathrm{ZnO}:(\mathrm{Co}, \mathrm{Al})$ & $0.04-0.12$ & Glass & $\begin{array}{l}\mathrm{RF} \\
\text { sputtering }\end{array}$ & & $\begin{array}{l}1 \times 10^{-2} \text { in } \\
\mathrm{Ar}\end{array}$ & & $>350$ & $0.21 \mu_{\mathrm{B}} / \mathrm{Co}$ & 59 \\
\hline $\mathrm{ZnO}: \mathrm{Mn}$ & $0.04-0.09$ & c-sapphire & $\begin{array}{l}\text { Reactive } \\
\text { sputtering }\end{array}$ & $200-380$ & & & $>400$ & $3 \mu_{\mathrm{B}} / \mathrm{Co}$ & 60 \\
\hline $\mathrm{ZnO}:(\mathrm{Mn}, \mathrm{Sn})$ & $0-0.3$ & & Implantation & & & $5 \min , 700^{\circ} \mathrm{C}$ & 250 & ferromagnetic & 24 \\
\hline $\mathrm{ZnO}: \mathrm{Mn}$ and $\mathrm{Sn}$ & $\begin{array}{l}\mathrm{Mn} \\
0.03, \mathrm{Sn}<0.1\end{array}$ & c-sapphire & PLD & $400-600$ & 0.02 & & $>300$ & ferromagnetic & 61 \\
\hline $\mathrm{ZnO}: \mathrm{Mn}$ and $\mathrm{Co}$ & $0.05-0.15$ & & $\begin{array}{l}\text { Crystalline } \\
\text { precursor }\end{array}$ & & & & & antiferromagnetic & 62 \\
\hline $\mathrm{ZnO}: \mathrm{Mn}$ and $\mathrm{Co}$ & $<0.05$ & bulk & Melt growth & $1000 \mathrm{C}$ & & & & paramagnetic & 63 \\
\hline $\mathrm{ZnO}: \mathrm{Co}$ & 0.1 & $\begin{array}{l}\mathrm{O} \text {-face } \\
\mathrm{ZnO}\end{array}$ & PLD & & & & & antiferromagnetic & 65 \\
\hline ZnO:Co & $<0.35$ & r-sapphire & MOCVD & $350-600 \mathrm{C}$ & 40 & $\begin{array}{l}20 \mathrm{~min}, 500 \mathrm{C} \text { in } \\
\text { vacuum }\end{array}$ & $>350$ & ferromagnetic & 65 \\
\hline $\mathrm{ZnO}: \mathrm{Co}$ and $\mathrm{Fe}$ & $<0.15$ & $\mathrm{SiO}_{2} / \mathrm{Si}$ & $\begin{array}{l}\text { Magnetron } \\
\text { sputtering }\end{array}$ & $600 \mathrm{C}$ & $2 \times 10^{-3}$ & $\begin{array}{l}10 \mathrm{~min} \\
600 \mathrm{C}, 10^{-5} \text { Torr }\end{array}$ & $>300$ & $\begin{array}{l}\text { Ferromagnetic , 12-15 } \\
{\mathrm{emu} / \mathrm{cm}^{3}}\end{array}$ & 66 \\
\hline $\mathrm{ZnO}: \mathrm{Mn}$ & 0.1 & r-sapphire & PLD & $650 \mathrm{C}$ & 0.1 & & $>300$ & $0.075 \mu_{\mathrm{B}} / \mathrm{Mn}$ & 39 \\
\hline $\mathrm{ZnO}: \mathrm{Mn}$ and $\mathrm{Cu}$ & $0.05-0.1$ & r-sapphire & PLD & $650 \mathrm{C}$ & 0.1 & & 400 & $0.1 \mu_{\mathrm{B}} / \mathrm{Mn}$ & 39,40 \\
\hline $\begin{array}{l}\mathrm{ZnO}: \mathrm{Sc}, \mathrm{Ti}, \mathrm{V}, \mathrm{Fe}, \\
\mathrm{Co} \text { or } \mathrm{Ni}\end{array}$ & 0.05 & r-sapphire & PLD & $600 \mathrm{C}$ & $0.1-750$ & & $>300$ & $\begin{array}{l}0.5 \mu_{\mathrm{B}} / \mathrm{Ti}, 5.9 \mu_{\mathrm{B}} / \mathrm{Co} \\
0.3 \mu_{\mathrm{B}} / \mathrm{Sc}\end{array}$ & 48 \\
\hline $\mathrm{ZnO}: \mathrm{Mn}$ & 0.02 & $\begin{array}{l}\text { Bulk } \\
\text { pellets }\end{array}$ & $\begin{array}{l}\text { Powder, } \\
\text { pellets and } \\
\text { laser-ablated } \\
\text { films } \\
\end{array}$ & $500 \mathrm{C}$ & & & $>300$ & $0.16 \mu_{\mathrm{B}} / \mathrm{Mn}$ & 34,35 \\
\hline $\mathrm{ZnO}: \mathrm{Cr}$ & & STO & PLD & & & & $>400$ & ferromagnetic & 38 \\
\hline $\mathrm{ZnO}: \mathrm{Mn}$ & 0.08 & tetrapods & evaporation & $600 \mathrm{C}$ & & & 43 & $(\mathrm{Zn}, \mathrm{Mn}) \mathrm{Mn}_{2} \mathrm{O}_{4}$ phases & 52 \\
\hline $\mathrm{ZnO}: \mathrm{Mn}$ & 0.05 & $\mathrm{ZnO}$ sub & PLD & $200-600 \mathrm{C}$ & & & 250 & High $T_{C}$ fpr lower $T_{G}$ & 49 \\
\hline $\mathrm{ZnO}: \mathrm{Mn}$ & 0.02 & $\begin{array}{l}\text { Poly } \\
\text { pellets and } \\
\text { thin films }\end{array}$ & $\begin{array}{l}\text { Powder and } \\
\text { PLD }\end{array}$ & $400-800 \mathrm{C}$ & 0.4 & & $>300$ & $0.18 \mu_{\mathrm{B}} / \mathrm{Mn}$ & 36 \\
\hline $\mathrm{ZnO}: \mathrm{Mn}$ & $0.02-0.1$ & pellets & powder & $400 \mathrm{C}$ & & $500-800 \mathrm{C}$ & $>300$ & Interfacial phase & 37 \\
\hline
\end{tabular}

Fukumura and coworkers [12]-[14] first reported the $\mathrm{ZnMnO}$ grown by a PLD. Up to $35 \%$, Mn was incorporated into the $\mathrm{ZnO}$ without degrading the crystallographic quality. This is in sharp contrast to III-V DMS, where about 5\%-9\% is tolerable before the crystallinity breaks down [67] and the precipitation is detectable by X-ray diffraction, transmission electron microscopy, and chemical profiling techniques. The high solubility of $\mathrm{Mn}$ in $\mathrm{ZnO}$ is due to the exactly half-filled 
$3 d$ orbitals of $\mathrm{Mn}^{2+}$. It costs a considerable amount of energy to add an electron with an opposite spin to the $3 d^{5}$ orbital, so that the Mn behaves similarly to $\mathrm{Zn}$ [67]. The reports of high solubility of $\mathrm{Mn}$ in $\mathrm{ZnO}$ led to many efforts on synthesis of the TM-doped $\mathrm{ZnO}$. The growth of these ferromagnetic materials by thin film techniques provides an excellent control of the TM dopant concentration and the ability to grow single-phase layers under optimized conditions, as measured by conventional $\mathrm{X}$-ray diffraction and transmission electron microscopy measurements. However, in some cases, the results concerning the existence of ferromagnetism have been somewhat controversial, partially because of the sensitivity of the resulting magnetic properties to the exact growth conditions and also to incomplete characterization of the magnetic properties. While some groups have reported ferromagnetism in ( $\mathrm{Zn}, \mathrm{TM}) \mathrm{O}$ systems, others report the observations of antiferromagnetic or spin-glass behavior. Important contributions in this regard have come from Kundaliya et al. [36] whose data strongly suggested that the observed ferromagnetism in the low-temperatureprocessed $\mathrm{Mn}-\mathrm{Zn}-\mathrm{O}$ system was due to a metastable phase (oxygen- vacancy-stabilized $\mathrm{Mn}_{2-x} \mathrm{Zn}_{x} \mathrm{O}_{3-\delta}$ ) rather than by carrier-induced interactions between separated $\mathrm{Mn}$ atoms in $\mathrm{ZnO}$, and also by García et al. [37] who reported that $\mathrm{MnO}_{2}-$ $\mathrm{ZnO}$ pellets exhibited a ferromagnetism due to the interface formed at the $\mathrm{ZnO}$ diffusion front into the $\mathrm{Mn}$ oxide. The reported values of $T_{C}$ scatter from 25 to $>550 \mathrm{~K}$. Similarly, conflicting results also exist concerning the distribution of TM ions such as Mn [28]. In RF magnetron sputter-deposited ( $\mathrm{Zn}$, $\mathrm{Mn}) \mathrm{O}$, Cheng and Chien [18] found Mn to be distributed homogeneously, while by contrast, Jin et al. [19] reported the clustering of $\mathrm{Mn}$ atoms. Once again, the exact growth conditions are crucial in determining the magnetic properties of the material at these high impurity concentrations [6]-[8], [66], [67]. A key issue in many of the published reports is whether the resulting material is indeed an alloy of TM elements with the host material or whether it remains as the host material with clusters, precipitates, or second phases that are responsible for the observed magnetic properties. A relatively complete characterization of the DMS would involve magnetic hysteresis measurements as well as fiel d-cooled and zero fiel d-cooled magnetization, magnetotransport, high-resolution transmission electron microscopy, chemical bonding information obtained from Xray photoelectron spectroscopy (XPS), and lattice location measurements by ion channeling or extended X-ray absorption fine structure (EXAFS). In most cases, such a detailed characterization is not carried out. The $\mathrm{ZnO}$ system provides an excellent platform for studying such effects, since most of the secondary phases that could form cannot explain the observed magnetism.

\section{AHE IN CoBALT-Doped ZnO FILMS}

A key issue to understanding and exploiting the ferromagnetism in TM-doped semiconductors materials is to elucidate the degree to which magnetic ordering couples to the carriers. One measurement that probes the carriers and magnetism is the AHE [71], [72]. Critical information about the physical mechanism responsible for ferromagnetism can be obtained by a measurement of AHE. The Hall resistivity of magnetic materials can be expressed as a sum of two terms, the ordinary part and anomalous one

$$
\rho_{x y}=R_{0} \cdot B+R_{s} \cdot \mu_{0} \cdot M
$$

where $R_{0}$ and $R_{s}$ are the ordinary and anomalous Hall coefficients, respectively, $B$ is the magnetic field, $\mu_{0}$ is the magnetic permeability, and $M$ is the magnetization. While the ordinary Hall effect results from the Lorenz force, the AHE is related to the asymmetric scattering of the charge carriers where the spinorbit interaction plays the important role [73]. It is known that two mechanisms of scattering are responsible for the AHE: the skew scattering (anisotropic amplitude of scattered wave packet in the presence of spin-orbit coupling) and the side jump (the changes in paths of charge carrier due to a lateral displacement) [74]. Recently, Jungwirth et al. [73] proposed a competing mechanism for the AHE in semimagnetic semiconductors. This theory relates the AHE to a Berry phase acquired by a quasiparticle wave function upon traversing closed paths on the spinsplit Fermi surface. For TM-doped oxides, previous results have shown an AHE in cobalt-doped $\mathrm{TiO}_{2}$ films with anatase crystals [74]-[76]. Rutile $\mathrm{TiO}_{2}$ has been also been reported [77], [78]. Similar results have not been reported for $\mathrm{ZnO}$. In this paper, the Hall effect and magnetoresistance measurement for the cobaltdoped $\mathrm{ZnO}$ films have been performed.

\section{EXPERIMENTAL PROCEDURES}

Epitaxial Co-doped $\mathrm{ZnO}$ films were grown by a conventional PLD. Laser ablation targets were prepared from high purity powders of $\mathrm{ZnO}$ (99.999\%), with $\mathrm{Co}_{3} \mathrm{O}_{4}$ (99.99\%) serving as the doping agent. The pressed targets were sintered in air. The targets were fabricated with a nominal composition ranging from 2.0 to 30 at.\% Co. A Lambda Physik KrF excimer laser was used as the ablation source. The laser energy density was 1-3 J/cm ${ }^{2}$ with a laser repetition rate of $1 \mathrm{~Hz}$ and target-tosubstrate distance of $6 \mathrm{~cm}$. The growth chamber exhibits a base pressure of $10^{-5}$ torr. Films were deposited onto single crystal c-plane oriented sapphire substrates. Film growth experiments were conducted over a temperature range of $400{ }^{\circ} \mathrm{C}-600^{\circ} \mathrm{C}$. An oxygen pressure ranging from $10^{-5}-10^{-2}$ torr was used for all film growth experiments. Film thicknesses were approximately 300-400 nm. X-ray diffraction was used to determine the crystallinity and secondary phase formation. Superconducting Quantum Interference Device (SQUID) magnetometry was used to characterize the ferromagnetic behavior of the doped films. Detailed microstructure characterization was performed using high-resolution transmission electron microscopy, X-ray diffraction, and EXAFS. All of these techniques showed the material to be a single crystal with an absence of detectable second phases and the Co soluble on substitutional sites. Roomtemperature magnetization was measured by a quantum design SQUID.

The Hall measurements were taken in a Physical Property Measurement System manufactured by Quantum Design Inc. The sample pucks were loaded into a 1-in diameter cylinder kept at 7.6-torr pressure of helium exchange gas. This cylinder is enclosed by a liquid helium Dewar which itself is enclosed 


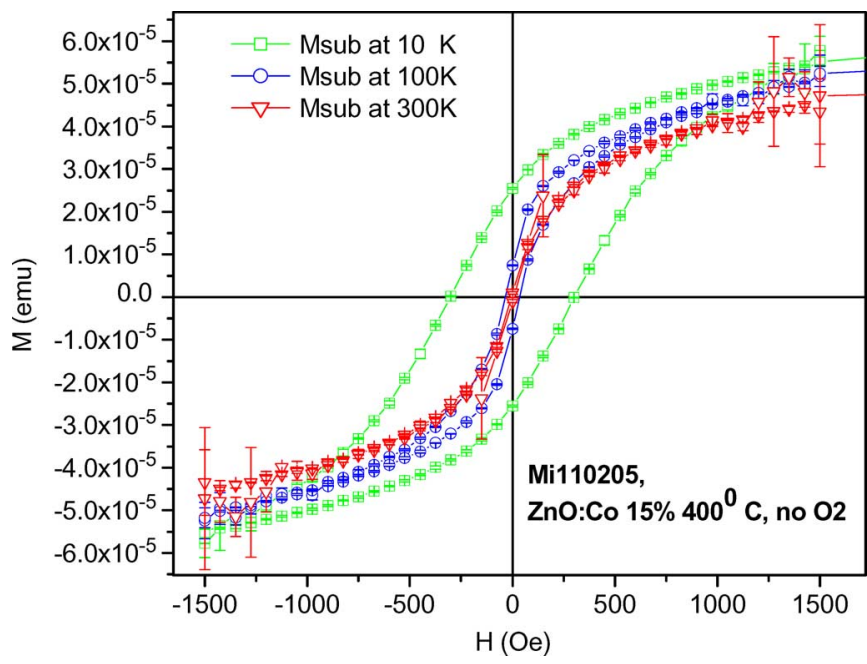

Fig. 2. SQUID magnetization data for Co-doped $\mathrm{ZnO}$ film. Total cobalt doping is 15 at.\%. The saturation magnetization corresponds to $0.35 \mu_{B} / \mathrm{Co}$.

by another Dewar filled with liquid nitrogen. The sample can be cooled down to $1.9 \mathrm{~K}$. The measurements were performed automatically by computer control.

\section{RESULTS AND DISCUSSION}

Co-doped epitaxial $\mathrm{ZnO}$ films realized for a growth temperature of $400{ }^{\circ} \mathrm{C}-600{ }^{\circ} \mathrm{C}$ and oxygen pressure of $10^{-5}$ torr exhibited a crystalline quality similar to that seen in a previous work on undoped films. The films are near single phase and epitaxial with a small amount of secondary phase seen in some of the XRD data. For cobalt doping 2 at.\% and greater, hysteretic loops are observed in the magnetization measurements at room temperature. Magnetization data for a $\mathrm{ZnO}$ film doped with 15 at.\% are shown in Fig. 2. Fig. 3 shows the magnetic field dependence of the Hall voltage at $10 \mathrm{~K}$ for Co-doped $\mathrm{ZnO}$ thin films. The negative linear slope indicates $n$-type majority carriers in the $\mathrm{ZnO}$ matrix.

There is some nonlinearity in the Hall data. This is due to an interference from the magnetoresistance curvature. The curvature is more pronounced when the high-field hall slopes are subtracted from the entire Hall curve. Contributions to the Hall resistivity due to the AHE are difficult to distinguish from the ordinary part. However, the contribution of the anomalous Hall can be seen by subtracting the ordinary Hall voltage contribution. It is expected that the anomalous part of the Hall voltage, which is proportional to magnetization, is dominant for lower magnetic field, whereas the ordinary part, which is proportional to the inverse of $n$, dominates the measurements at higher magnetic field [73], [76]. In order to investigate the magnetic field dependence of the Hall voltage, the Hall effect measurement was performed over a wide range of magnetic fields. From (1), the first term denotes ordinary Hall effect and the second term denotes the AHE, where the latter term dominates over the former term in typical ferromagnetic materials. If the charge carrier is spin polarized, the Hall voltage versus $B\left(B \sim \mu_{0} H\right)$ curve should behave like a magnetization hysteresis curve. Fig. 3 shows the Hall voltage for a $\mathrm{ZnO}$
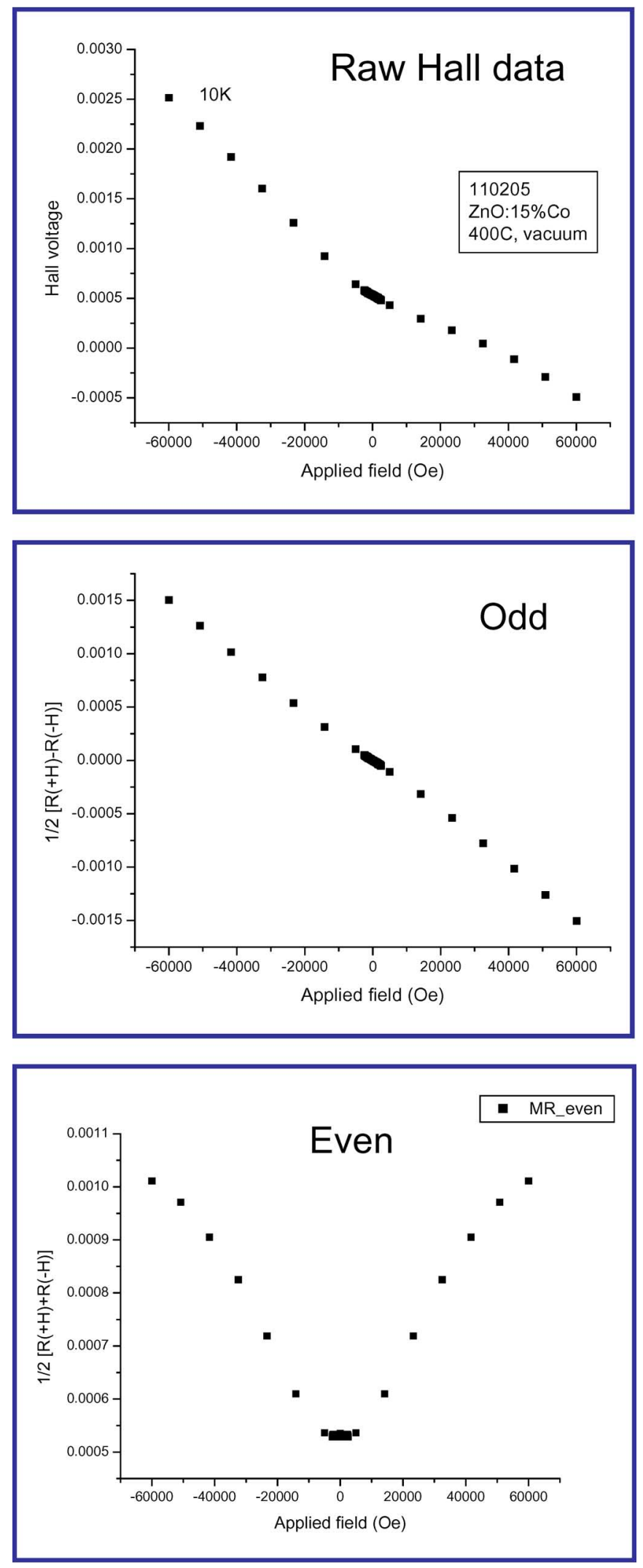

Fig. 3. Hall voltage for a $\mathrm{ZnO}$ film doped with $15 \%$ cobalt. Nonlinear AHE terms can be extracted by subtracting the ordinary Hall voltage derived from the high-field behavior. The inflection in the curve at low fields indicates a nonzero value for $R_{s}$ in (1). Extracting the odd and even field components from the raw data produces two new graphs: The even terms have the shape of the magnetoresistance component and the odd terms give the Hall component. The unit of Hall voltage is volts. 


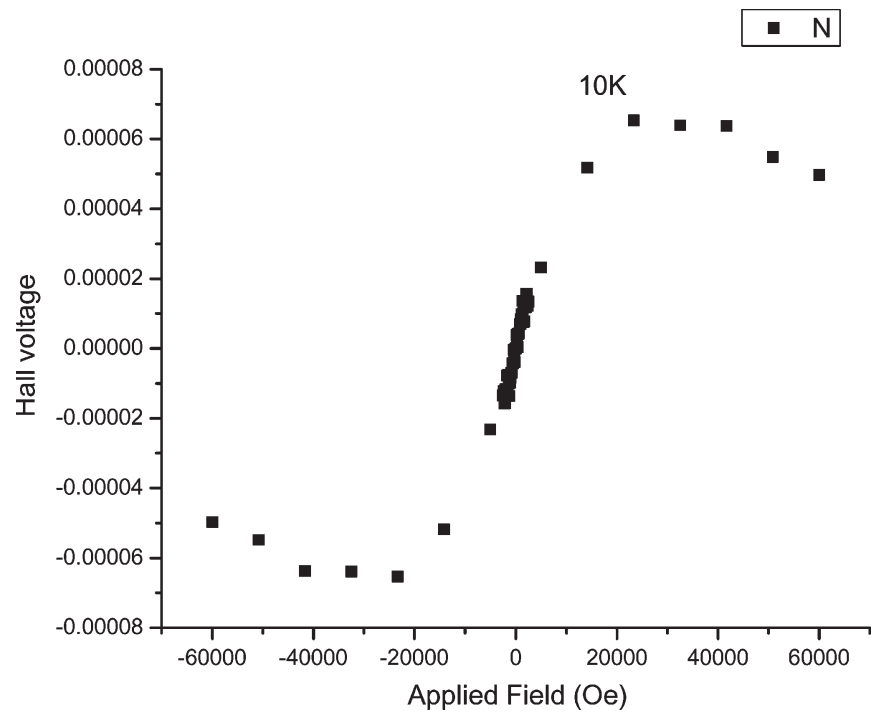

Fig. 4. Extracted anomalous Hall voltage for $\mathrm{ZnO}$ film doped with 15 at.\% cobalt.

film doped with $15 \%$ cobalt. With the ordinary Hall effect dominant, nonlinear AHE terms can be extracted by subtracting the ordinary Hall voltage, derived from the high-field behavior. The inflection in the curve at low fields indicates a nonzero value for $R_{s}$ in (1).

Extracting the odd and even field components from the raw data produces two new graphs: The even terms have the shape of the magnetoresistance component, and the odd terms give the Hall component. Note that the even terms are of similar shape as seen for the raw resistivity data. Subtracting the high-field slope from the entire odd field component graph produces a better representation of the AHE as compared to using the raw data. This is shown in Fig. 4. The overall shape of the anomalous Hall voltage is similar to a magnetization curve as expected.

It has been suggested that the appearance of an AHE could be attributed to the spin scattering due to ferromagnetic nanoparticles distributed in a nonmagnetic semiconducting matrix [76]. Selected area electron diffraction only shows peaks associated with $\mathrm{ZnO}$. Fig. 5 shows a high-resolution TEM image and selected area diffraction pattern for a Co-doped $\mathrm{ZnO}$ film. No evidence is seen for cobalt metal precipitates, or other secondary phases are seen in the selected area diffraction.

\section{SPIN RELAXATION}

Detailed time-resolved magneto-PL results from undoped and $\mathrm{Mn}$-doped $\mathrm{ZnO}$ structures have recently been performed in an effort to detect the polarized light emission [79]. The preliminary conclusions can be summarized as follows.

1) In an applied magnetic field, the $\mathrm{ZnO}$ PL becomes polarized to about $10 \%$ at $6 \mathrm{~T}$. The polarization degree decreases with increasing emission energy. The behavior is similar for both undoped and doped $\mathrm{ZnO}$. Data for $\mathrm{Zn}(\mathrm{Mn}, \mathrm{Mg}) \mathrm{O} / \mathrm{ZnO} / \mathrm{AlGaN}$ spin LEDs grown on sapphire are shown in Fig. 6.

2) No transient PL polarization is noticeable by monitoring the high-energy side of the PL emission, as shown in
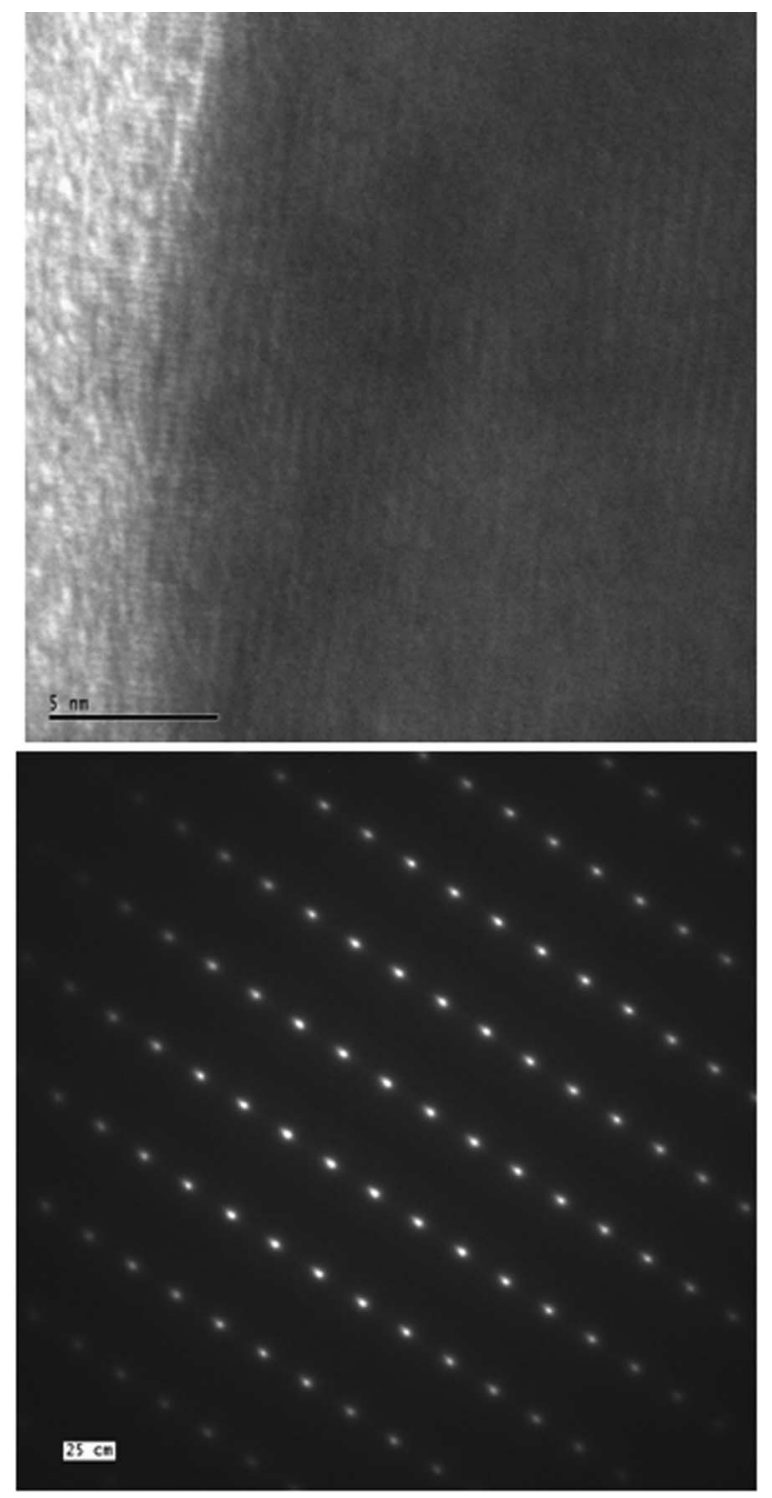

Fig. 5. High-resolution TEM image and selected area electron diffraction pattern for a $\mathrm{ZnO}$ film doped with 15 at.\% cobalt. The electron diffraction pattern corresponds to the wurtzite structure. The scale marker is $5 \mathrm{~nm}$.

Fig. 7. This can be attributed to very fast spin relaxation between the Zeeman split spin levels, faster than the experimental resolution about $20 \mathrm{ps}$, even near $k=0$. By monitoring the low-energy side of the PL band, on the other hand, a polarization rising (although weak) with time seems to occur indicating a slower spin relaxation process associated with the monitored emission. This energy dependence is opposite to what we observed in the InGaN QW [68]-[70].

3) No information on spin relaxation accompanying the energy relaxation of hot carriers, which is relevant to spin injection from barrier materials, could be obtained from the present results. For that optical orientation experiments have to be performed; although given that the valence band structure of $\mathrm{ZnO}$ is rather similar to that of GaN, the outlook is not hopeful [68]-[70]. It appears that the spin relaxation occurs mostly during the energy relaxation processes at a high momentum that is 


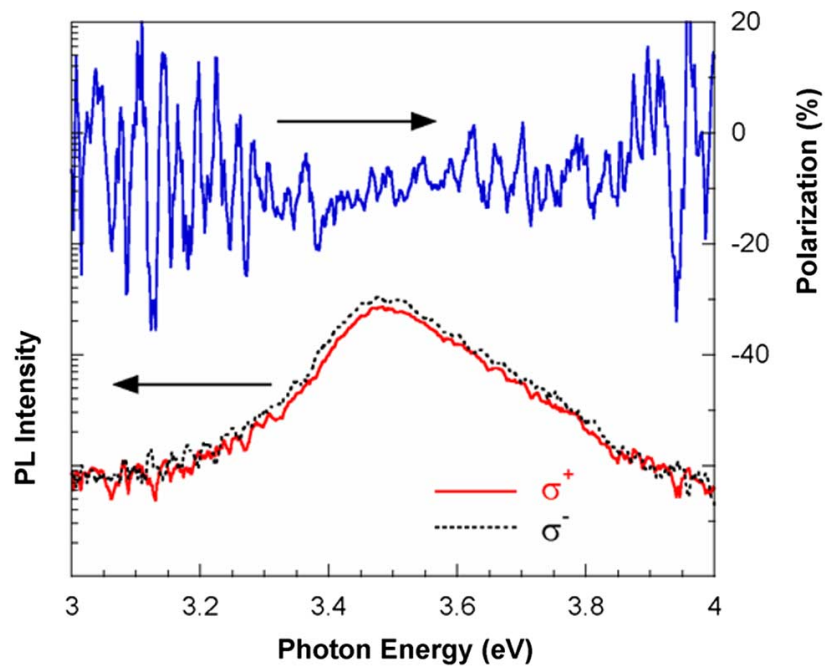

Fig. 6. PL spectra at $2 \mathrm{~K}$ from $\mathrm{Zn}(\mathrm{Mn}, \mathrm{Mg}) \mathrm{O} / \mathrm{ZnO} / \mathrm{AlGaN}$ spin LEDs grown on sapphire, as well as their polarization properties at.

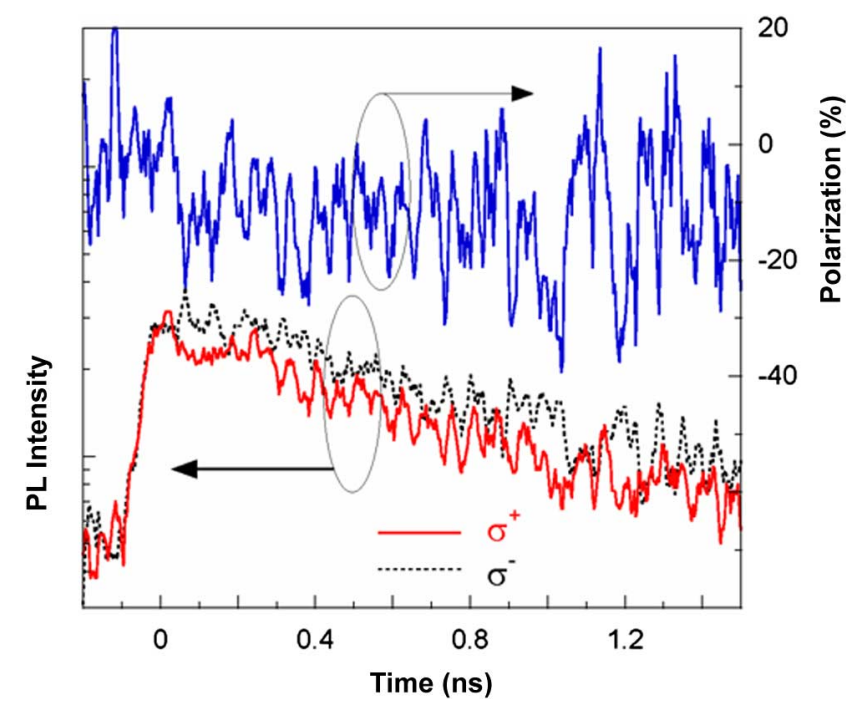

Fig. 7. Time-resolved PL intensity measured from $\mathrm{ZnO}$ (detected within the spectral range of $365-432 \mathrm{~nm}$ ) from $\mathrm{Zn}(\mathrm{Mn}, \mathrm{Mg}) \mathrm{O} / \mathrm{ZnO} / \mathrm{AlGaN}$ spin LED, as well as the polarization properties at a field of 6T(bottom).

beyond the reach of commonly available experimental techniques, as is true for the previously reported $\mathrm{InGaN}$ quantum wells [66]-[68].

\section{Future Work}

More detailed studies of the carrier type and concentration dependence of magnetization are needed in $\mathrm{ZnO}$. In particular, methods such as EXAFS or XPS that establish lattice location or chemical state should be applied in order to give more insight into possible mechanisms for the observed ferromagnetism. Spin polarized injection, transport and detection experiments in $\mathrm{ZnO}$ or $\mathrm{ZnCdO} / \mathrm{ZnMgO}$ heterostructures are lacking at present as they are clear demonstrations of carrier- or lightinduced ferromagnetism. Device demonstrations of the exploitation of spin effects in oxides are the key to advancing both the science and technology of these materials for spintronic applications.

\section{ACKNOWLEDGMENT}

The authors would like to thank G. Thaler and Y. D. Park for their valuable collaborations on these projects.

\section{REFERENCES}

[1] P. Kacman, "Spin interactions in DMS and magnetic semiconductor structures," Semicond. Sci. Technol., vol. 16, no. 4, pp. R25-R39, Apr. 2001.

[2] S. A. Wolf, D. D. Awschalom, R. A. Buhrman, J. M. Daughton, S. von Molnár, M. L. Roukes, A. Y. Chtchelkanova, and D. M. Treger, "Spintronics: A spin-based electronics vision for the future," Science, vol. 294, no. 5546, pp. 1488-1495, Nov. 2001.

[3] S. J. Pearton, C. R. Abernathy, M. E. Overberg, G. T. Thaler, D. P. Norton, N. Theodoropoulou, A. F. Hebard, Y. D. Park, F. Ren, J. Kim, and L. A. Boatner, "Wide bandgap ferromagnetic semiconductors and oxides," J. Appl. Phys., vol. 93, no. 1, pp. 1-21, Jan. 2003.

[4] J. M. D. Coey, M. Venkatesan, and C. B. Fitzgerald, "Donor impurity band exchange in dilute ferromagnetic oxides," Nat. Mater, vol. 4, no. 4, pp. 173-176, Apr. 2005.

[5] K. Sato and H. Katayama-Yoshida, "First principles design for semiconductor spintronics," Semicond. Sci. Technol., vol. 17, no. 4, pp. 367-376, Apr. 2002.

[6] W. Prellier, A. Fouchet, and B. Mercey, "Oxide-diluted magnetic semiconductors: A review of the experimental status," J. Phys., Condens. Matter, vol. 15, no. 37, pp. R1583-R1601, Sep. 2003.

[7] T. Fukumura, Y. Yamada, H. Toyosaki, T. Hasegawa, H. Koinuma, and M. Kawasaki, "Exploration of oxide-based diluted magnetic semiconductors toward transparent spintronics," Appl. Surface. Sci., vol. 223, no. 1-3, pp. 62-67, Feb. 2004.

[8] S. J. Pearton, W. H. Heo, M. Ivill, D. P. Norton, and T. Steiner, "Dilute magnetic semiconducting oxides," Semicond. Sci. Technol., vol. 19, no. 10, pp. R59-R76, Oct. 2004.

[9] I. Zutic, J. Fabian, and S. D. Sarma, "Spintronics: Fundamentals and applications," Rev. Mod. Phys., vol. 76, no. 2, pp. 323-410, Apr. 2004.

[10] T. Dietl, H. Ohno, F. Matsukura, J. Cibert, and D. Ferrand, "Zener model description of ferromagnetism in zinc-blende magnetic semiconductors," Science, vol. 287, no. 5455, pp. 1019-1022, Feb. 2000.

[11] K. Sato and H. Katayama-Yoshida, "Stabilization of ferromagnetic states by electron doping in Fe-,Co-, or Ni-doped ZnO," Jpn. J. Appl. Phys., vol. 40, no. 4, pp. L334-L336, Apr. 2001.

[12] T. Fukumura, Z. Jin, M. Kawasaki, T. Shono, T. Hasegawa, S. Koshihara, and H. Koinuma, "Magnetic properties of Mn-doped ZnO," Appl. Phys. Lett., vol. 78, no. 7, pp. 958-960, Feb. 2001.

[13] T. Fukumura, Z. Jin, A. Ohtomo, H. Koinuma, and M. Kawasaki, "An oxide-diluted magnetic semiconductor: Mn-doped ZnO," Appl. Phys. Lett., vol. 75, no. 21, pp. 3366-3368, Nov. 1999.

[14] Z. Jin, T. Fukumura, M. Kawasaki, K. Ando, H. Saito, T. Sekiguchi, Y. Z. Yoo, M. Murakami, Y. Matsumoto, T. Hasegawa, and H. Koinuma, "High throughput fabrication of transition-metal-doped epitaxial $\mathrm{ZnO}$ thin films: A series of oxide-diluted magnetic semiconductors and their properties," Appl. Phys. Lett., vol. 78, no. 24, pp. 3824-3826, Jun. 2001.

[15] J.-H. Kim, H. Kim, D. Kim, Y.-E. Ihm, and W.-K. Choo, "Magnetic properties of epitaxially grown semiconducting $\mathrm{Zn}_{1-x} \mathrm{Co}_{x} \mathrm{O}$ thin films by pulsed laser deposition," J. Appl. Phys., vol. 92, no. 10, pp. 6066-6071, Nov. 2002.

[16] A. Tiwari, C. Jin, A. Kvit, D. Kumar, J. F. Muth, and J. Narayan, "Structural, optical and magnetic properties of diluted magnetic semiconducting $\mathrm{Zn}_{1-x} \mathrm{Mn}_{x} \mathrm{O}$ films," Solid State Commun., vol. 121, no. 6, pp. 371-373, Feb. 2002.

[17] S. J. Han, T. H. Jang, Y. B. Kim, B. G. Park, J. H. Park, and Y. H. Jeong, "Magnetism in Mn-doped $\mathrm{ZnO}$ bulk samples prepared by solid state reaction," Appl. Phys. Lett., vol. 83, no. 5, pp. 920-922, Aug. 2003.

[18] X. M. Cheng and C. L. Chien, "Magnetic properties of epitaxial Mndoped $\mathrm{ZnO}$ thin films," J. Appl. Phys., vol. 93, no. 10, pp. 7876-7879, May 2003.

[19] Z. Jin, Y.-Z. Yoo, T. Sekiguchi, T. Chikyow, H. Ofuchi, H. Fujioka, M. Oshima, and H. Koinuma, "Blue and ultraviolet cathodoluminescence from Mn-doped epitaxial ZnO thin films," Appl. Phys. Lett., vol. 83, no. 1, pp. 39-41, Jul. 2003.

[20] K. Ando, H. Saito, V. Zayets, and M. C. Debnath, "Optical properties and functions of dilute magnetic semiconductors," J. Phys., Condens. Matter, vol. 16, no. 48, pp. S5541-S5548, Dec. 2004.

[21] S. W. Jung, S.-J. An, G.-C. Yi, C. U. Jung, S.-I. Lee, and S. Cho, "Ferromagnetic properties of $\mathrm{Zn}_{1-x} \mathrm{Mn}_{x} \mathrm{O}$ epitaxial thin films," Appl. Phys. Lett., vol. 80, no. 24, pp. 4561-4563, Jun. 2002. 
[22] Y. W. Heo, M. P. Ivill, K. Ip, D. P. Norton, and S. J. Pearton, "Effects of high-dose Mn implantation into $\mathrm{ZnO}$ grown on sapphire," Appl. Phys. Lett., vol. 84, no. 13, pp. 2292-2294, Mar. 2004.

[23] S. W. Lim, M. C. Jeong, M. H. Ham, and J. M. Hyoung, "Hole-mediated ferromagnetic properties in ZnMnO," Jpn. J. Appl. Phys., vol. 43, no. 2, pp. L280-L283, Feb. 2004.

[24] D. P. Norton, S. J. Pearton, A. F. Hebard, N. Theodoropoulou, L. A. Boatner, and R. G. Wilson, "Ferromagnetism in Mn-implanted ZnO:Sn single crystals," Appl. Phys. Lett., vol. 82, no. 2, pp. 239-241, Jan. 2003.

[25] K. Ando, H. Saito, Z. Jin, T. Fukumura, M. Kawasaki, Y. Matsumoto, and $\mathrm{H}$. Koinuma, "Magneto-optical properties of $\mathrm{ZnO}$-based diluted magnetic semiconductors," J. Appl. Phys., vol. 89, no. 11, pp. 7284-7286, Jun. 2001.

[26] K. Ueda, H. Tabata, and T. Kawai, "Magnetic and electric properties of transition-metal-doped $\mathrm{ZnO}$ films," Appl. Phys. Lett., vol. 79, no. 7, pp. 988-990, Aug. 2001.

[27] K. Ando, H. Saito, Z. Jin, T. Fukumura, M. Kawasaki, Y. Matsumoto, and H. Koinuma, "Large magneto-optical effect in an oxide diluted magnetic semiconductor $\mathrm{Zn}_{1-x} \mathrm{Co}_{x} \mathrm{O}$," Appl. Phys. Lett., vol. 78, no. 18, pp. 27002702, Apr. 2001

[28] Y. M. Cho, W. K. Choo, H. Kim, D. Kim, and Y. E. Ihm, "Effects of rapid thermal annealing on the ferromagnetic properties of sputtered $\mathrm{Zn}_{1-x}\left(\mathrm{Co}_{0.5} \mathrm{Fe}_{0.5}\right)_{x} \mathrm{O}$ thin films," Appl. Phys. Lett., vol. 80, no. 18, pp. 3358-3360, May 2002.

[29] S. W. Yoon, S.-B. Cho, S. C. We, S. Yoon, B. J. Suh, H. K. Song, and Y. J. Shin, "Magnetic properties of ZnO-based diluted magnetic semiconductors," J. Appl. Phys., vol. 93, no. 10, pp. 7879-7882, May 2003.

[30] K. Sato and H. Katayama-Yoshida, "Materials design of transparent and half-metallic ferromagnets in V or Cr-doped $\mathrm{ZnS}$, ZnSe and ZnTe," Jpn. J. Appl. Phys., vol. 40, no. 7, pp. L651-L653, Jul. 2001.

[31] K. Sato and H. Katayama-Yoshida, "Ferromagnetism in a transition metal atom doped ZnO," Physica E, vol. 10, no. 1, pp. 251-255, May 2001.

[32] H. Katayama-Yoshida and K. Sato, "Materials design for semiconductor spintronics by ab initio electronic-structure calculation," Physica B, vol. 327, no. 2, pp. 337-343, Apr. 2003.

[33] K. Sato and H. Katayama-Yoshida, "Electronic structure and ferromagnetism of transition-metal-impurity-doped zinc oxide," Physica B, vol. 308-310, no. 1, pp. 904-907, Dec. 2001.

[34] P. Sharma, A. Gupta, K. V. Rao, F. J. Owens, R. Sharma, R. Ahuja, J. M. Osorio Guillen, B. Johansson, and G. A. Gehring, "Ferromagnetism above room temperature in bulk and transparent thin films of Mn-doped $\mathrm{ZnO}$," Nat. Mater., vol. 2, no. 10, pp. 673-677, Oct. 2003.

[35] P. Sharma, A. Gupta, F. J. Owens, A. Inoue, and K. V. Rao, "Room temperature spintronic material-Mn-doped $\mathrm{ZnO}$ revisited," J. Magn. Magn. Mater, vol. 282, no. 11, pp. 115-121, Nov. 2004

[36] D. C. Kundaliya, S. B. Ogale, S. E. Lofland, S. Dhar, C. J. Metting, S. R. Shinde, Z. Ma, B. Varughese, K. V. Ramanujachary, L. Salamanca-Riba, and T. Venkatesan, "On the origin of high-temperature ferromagnetism in the low-temperature-processed $\mathrm{Mn}-\mathrm{Zn}-\mathrm{O}$ system," Nat. Mater., vol. 3, no. 10 , pp. 709-714, Oct. 2004

[37] M. A. García, M. L. Ruiz-González, A. Quesada, J. L. Costa-Krämer, J. F. Fernández, S. J. Khatib, A. Wennberg, A. C. Caballero, M. S. Martín-González, M. Villegas, F. Briones, J. M. González-Calbet, and A. Hernando, "Interface double-exchange ferromagnetism in the Mn-Zn-O system: New class of biphase magnetism," Phys. Rev. Lett., vol. 94 , no. 21, p. 217206 , Jun. 2005.

[38] I. Satoh and T. Kobayashi, "Magnetic and optical properties of novel magnetic semiconductor $\mathrm{Cr}$-doped $\mathrm{ZnO}$ and its application to all oxide p-i-n diode," Appl. Surf. Sci., vol. 216, no. 1, pp. 603-608, Jun. 2003.

[39] N. H. Hong, V. Brize, and J. Sakai, "Mn-doped $\mathrm{ZnO}$ and (Mn, Cu)doped $\mathrm{ZnO}$ thin films: Does the $\mathrm{Cu}$ doping indeed play a key role in tuning the ferromagnetism?" Appl. Phys. Lett., vol. 86, no. 8, p. 082505 , Feb. 2005.

[40] N. H. Hong, J. Sakai, and A. Hassini, "Magnetism in V-doped $\mathrm{ZnO}$ thin films," J. Phys., Condens. Matter, vol. 17, no. 1, pp. 199-204, Jan. 2005.

[41] Y. H. Jeong, S. J. Han, J. H. Park, and Y. H. Lee, "A critical examination of room temperature ferromagnetism in transition metal-doped oxide semiconductors," J. Magn. Mag. Mater., vol. 272-276, no. 3, pp. 1976-1980, May 2004.

[42] D. A. Schwartz, K. R. Kittilstved, and D. R. Gamelin, "Above-roomtemperature ferromagnetic $\mathrm{Ni}^{2+}$-doped $\mathrm{ZnO}$ thin films prepared from colloidal diluted magnetic semiconductor quantum dots," Appl. Phys. Lett., vol. 85, no. 8, pp. 1395-1397, Aug. 2004.

[43] P. V. Radovanovic and D. R. Gamelin, "High-temperature ferromagnetism in $\mathrm{Ni}^{2+}$-doped $\mathrm{ZnO}$ aggregates prepared from colloidal diluted magnetic semiconductor quantum dots," Phys. Rev. Lett., vol. 91, no. 15, p. 157 202, Oct. 2003
[44] T. Mizokawa, T. Nambu, A. Fujimori, T. Fukumura, and M. Kawasaki, "Electronic structure of the oxide-diluted magnetic semiconductor $\mathrm{Zn}_{1-x} \mathrm{Mn}_{x}$ O," Phys. Rev. B, Condens. Matter, vol. 65, no. 8, p. 085209 , Feb. 2002.

[45] C.-H. Chien, S. H. Chiou, G. Y. Guo, and Y.-D. Yao, "Electronic structure and magnetic moments of $3 \mathrm{~d}$ transition metal-doped $\mathrm{ZnO}$," J. Magn. Magn. Mater., vol. 282, no. 11, pp. 275-278, Nov. 2004.

[46] X. Feng, "Electronic structures and ferromagnetism of $\mathrm{Cu}-$ and $\mathrm{Mn}$ doped ZnO," J. Phys., Condens. Matter., vol. 16, no. 24, pp. 4251-4260, Jun. 2004.

[47] S. Y. Yun, G.-B. Cha, Y. Kwon, S. Cho, S. C. Soon, and C. Hong, "First-principles calculations on magnetism of transition metal doped zinc oxide," J. Magn. Magn. Mater, vol. 272-276, no. 5, pp. E1563-E1564, May 2004.

[48] M. Venkatesan, C. B. Fitzgerald, J. G. Lunney, and J. M. D. Coey, "Anisotropic ferromagnetism in substituted zinc oxide," Phys. Rev. Lett., vol. 93, no. 17, p. 177 206, Oct. 2004.

[49] K. W. Nielsen, J. B. Phillip, M. Opel, A. Erb, J. Simon, L. Alff, and R. Gross, "Ferromagnetism in Mn-doped $\mathrm{ZnO}$ due to impurity bands," Superlatt. Microstruct., vol. 37, no. 5, pp. 327-332, May 2005.

[50] M. Kunisu, F. Oba, H. Ikeno, I. Tananka, and T. Yamamoto, "Local environment of $\mathrm{Mn}$ dopant in $\mathrm{ZnO}$ by near-edge $\mathrm{x}$-ray absorption fine structure analysis," Appl. Phys. Lett., vol. 86, no. 12, p. 121902 , Mar. 2005.

[51] E. Rita, U. Wahl, J. G. Correia, E. Alves, and J. C. Soares, "Lattice location and thermal stability of implanted $\mathrm{Fe}$ in $\mathrm{ZnO}$," Appl. Phys. Lett., vol. 85 , no. 21 , pp. 4899-4901, Nov. 2004

[52] R. K. Zheng, H. Liu, X. X Zhang, V. A. L. Roy, and A. B. Djurisic, "Exchange bias and the origin of magnetism in Mn-doped $\mathrm{ZnO}$ tetrapods," Appl. Phys. Lett., vol. 85, no. 16, pp. 2589-2591, Sep. 2004.

[53] T. Wakano, N. Fujimura, Y. Morinaga, N. Abe, A. Ashida, and T. Ito, "Magnetic and magneto-transport properties of $\mathrm{ZnO}$ :Ni films," Physica E, vol. 10, no. 1, pp. 260-264, May 2001.

[54] H. Saeki, H. Tabata, and T. Kawai, "Magnetic and electric properties of vanadium doped ZnO films," Solid State Commun., vol. 120, no. 11, pp. 439-441, Nov. 2001.

[55] D. P. Norton, M. E. Overberg, S. J. Pearton, K. Pruessner, J. D. Budai, L. A. Boatner, M. F. Chisholm, J. S. Lee, Z. G. Khim, Y. D. Park, and R. G. Wilson, "Ferromagnetism in cobalt-implanted ZnO," Appl. Phys. Lett., vol. 83, no. 26, pp. 5488-5490, Dec. 2003.

[56] H. J. Lee, S. Y. Jeong, C. R. Cho, and C. H. Park, "Study of diluted magnetic semiconductor: Co-doped ZnO," Appl. Phys. Lett., vol. 81, no. 21, pp. 4020-4022, Nov. 2002

[57] S. J. Hahn, J. W. Song, C. H. Yang, S. H. Park, J. H. Park, Y. H Jeong, and K. W. Rhie, "A key to room-temperature ferromagnetism in Fe-doped ZnO: Cu," Appl. Phys. Lett., vol. 81, no. 22, pp. 4212-4214, Nov. 2002.

[58] K. Rode, A. Anane, R. Mattana, J.-P. Contour, O. Durand, and R. LeBourgeois, "Magnetic semiconductors based on cobalt substituted ZnO," J. Appl. Phys., vol. 93, no. 10, pp. 7676-7679, May 2003.

[59] S. G. Yang, A. B. Pakhomov, S. T. Hung, and C. Y. Wong, "Room temperature magnetism in sputtered (Zn,Co)O films," IEEE Trans. Magn., vol. 38, no. 5, pp. 2877-2879, Sep. 2002.

[60] N. Theodoropoulou, G. P. Berera, V. Misra, P. LeCalir, J. Philip, J. S. Moodera, B. Satapi, and T. Som, Evidence for High Temperature Ferromagnetism in $Z n_{1-x} M n_{x} O$ thin films. to be published.

[61] M. Ivill, S. J. Pearton, D. P. Norton, J. Kelly, and A. F. Hebard, "Magnetization dependence on electron density in epitaxial $\mathrm{ZnO}$ thin films codoped with Mn and Sn," J. Appl. Phys., vol. 97, no. 5, p. 053 904, Mar. 2005.

[62] G. Lawes, A. S. Risbud, A. P. Ramirez, and R. Seshadri, "Absence of ferromagnetism in $\mathrm{Co}$ and $\mathrm{Mn}$ substituted polycrystalline $\mathrm{ZnO}$," Phys. Rev. B, Condens. Matter, vol. 71, no. 4, p. 045 201, Jan. 2005.

[63] M. H. Kane, K. Shalini, C. J. Summers, R. Varatharajan, J. Nause, C. R. Vestal, Z. J. Zhang, and I. T. Ferguson, "Magnetic properties of bulk $\mathrm{Zn}_{1-x} \mathrm{Mn}_{x} \mathrm{O}$ and $\mathrm{Zn}_{1-x} \mathrm{Co}_{x} \mathrm{O}$ single crystals," J. Appl. Phys., vol. 97, no. 2, p. 023906 , Jan. 2005.

[64] N. Jedrecy, H. J. von Bardeleben, Y. Zheng, and J.-L. Cantin, "Electron paramagnetic resonance study of $\mathrm{Zn}_{1-x} \mathrm{Co}_{x} \mathrm{O}$ : A predicted hightemperature ferromagnetic semiconductor," Phys. Rev. B, Condens. Matter, vol. 69, no. 4, p. 041 308, Jan. 2004.

[65] A. C. Tuan, J. D. Bryan, A. B. Pakhomov, V. Shutthanandan, S. Thevuthasan, D. E. McCready, D. Gaspar, M. H. Engelhard, J. W. Rogers, Jr., K. Krishnan, D. R. Gamelin, and S. A. Chambers, "Epitaxial growth and properties of Co-doped $\mathrm{ZnO}$ on sapphire substrates," Phys. Rev. B, Condens. Matter, vol. 70, no. 6, p. 054 424, Aug. 2004.

[66] T. Fukumura, H. Toyosaki, and Y. Yamada, "Magnetic oxide semiconductors," Semicond. Sci. Technol., vol. 20, no. 4, pp. S103-S111, Apr. 2005. 
[67] C. Liu, F. Yun, and H. Morkoç, "Ferromagnetism of $\mathrm{ZnO}$ and GaN: A review," J. Mater. Sci., Mater. Electron., vol. 16, no. 9, pp. 555-597, Sep 2005.

[68] I. A. Buyanova, M. Izadifard, L. Storasta, W. M. Chen, J. Kim, F. Ren, G. Thaler, C. R. Abernathy, S. J. Pearton, C.-C. Pan, G.-T. Chen, J.-I. Chyi, and J. M. Zavada, "Optical and electrical characterization of (Ga,Mn)N/InGaN MOW LEDs," J. Electron. Mater, vol. 33, no. 5, pp. 467-472, May 2004.

[69] I. A. Buyanova, M. Izadifard, W. M. Chen, J. Kim, F. Ren, G. Thaler, C. R. Abernathy, S. J. Pearton, C. Pan, G. Chen, J. Chyi, and J. M. Zavada, "On the origin of spin loss in GaMnN/InGaN light-emitting diodes," Appl. Phys. Lett., vol. 84, no. 14, pp. 2599-2601, Apr. 2004.

[70] I. A. Buyanova, J. P. Bergman, W. M. Chen, G. Thaler, R. Frazier, C. R. Abernathy, S. J. Pearton, J. Kim, F. Ren, F. V. Kyrychenko, C. J. Stanton, C.-C. Pan, G.-T. Chen, J.-I. Chyi, and J. M. Zavada, "Optical study of spin injection dynamics in InGaN/GaN quantum wells with $\mathrm{GaMnN}$ injection layers," J. Vac. Sci. Technol. B, Microelectron. Processs. Phenom., vol. 22, no. 6, pp. 2668-2673, Nov. 2004

[71] H. Ohno, "Making nonmagnetic semiconductors ferromagnetic," Science, vol. 281, no. 5379, pp. 951-956, Aug. 1998.

[72] L. Berger and G. Bergmann, The Hall Effect and Its Applications, C. L. Chien and C. R. Westgate, Eds. New York: Plenum, 1979, p. 55.

[73] T. Jungwirth, Q. Niu, and A. H. MacDonald, "Anomalous hall effect in ferromagnetic semiconductors," Phys. Rev. Lett., vol. 88, no. 22, p. 207 208, May 2002.

[74] Y. Matsumoto, M. Murakami, T. Shono, T. Hasegawa, T. Fukumura, M. Kawasaki, P. Ahmet, T. Chikyow, S.-Y. Koshihara, and H. Koinuma, "Room-temperature ferromagnetism in transparent transition metal-doped titanium dioxide," Science, vol. 291, no. 5505, pp. 854-856, Feb. 2001.

[75] Y. Yamada, H. Toyosaki, A. Tsukazaki, T. Fukumura, K. Tamura, Y. Segawa, K. Nakajima, T. Aoyama, T. Chikyow, T. Hasegawa, H. Koinuma, and M. Kawasaki, "Epitaxial growth and physical properties of a room temperature ferromagnetic semiconductor: Anatase phase $\mathrm{Ti}_{1-x} \mathrm{Co}_{x} \mathrm{O}_{2+}$, , J. Appl. Phys., vol. 96, no. 9, p. 5097, Nov. 2004.

[76] S. R. Shinde, S. B. Ogale, J. S. Higgins, H. Zheng, A. J. Millis, V. N. Kulkarni, R. Ramesh, R. L. Greene, and T. Venkatesan, "Cooccurrence of superparamagnetism and anomalous hall effect in highly reduced cobalt-doped rutile $\mathrm{TiO}_{2-\delta}$ films," Phys. Rev. Lett., vol. 92, no. 16, p. 166601 , Apr. 2004.

[77] H. Toyosaki, T. Fukumura, Y. Yamada, K. Nakajima, T. Chikyow, T. Hasegawa, H. Koinuma, and M. Kawasaki, "Anomalous hall effect governed by electron doping in a room-temperature transparent ferromagnetic semiconductor," Nat. Mater, vol. 3, no. 4, pp. 221-224, Apr. 2004.

[78] Y. Matsumoto, R. Takahashi, M. Murakami, T. Koida, X.-J. Fan, T. Hasegawa, T. Fukumura, M. Kawasaki, S.-Y. Koshihara, and $\mathrm{H}$. Koinuma, "Ferromagnetism in co-doped $\mathrm{TiO}_{2}$ rutile thin films grown by laser molecular beam epitaxy," Jpn. J. Appl. Phys., vol. 40, no. 11B, pp. L1204-L1206, Nov. 2001

[79] I. Buyanova, W. M. Chen, M. Ivill, R. Pate, D. P. Norton, S. J. Pearton, J. Dong, A. Osinsky, B. Hertog, A. Dabiran, and P. P. Chow, "Optical characterization of $\mathrm{ZnMnO}$-based dilute magnetic semiconductor structures," J. Vac. Sci. Technol., vol. 24, no. 1, pp. 259-264, Jan. 2006.

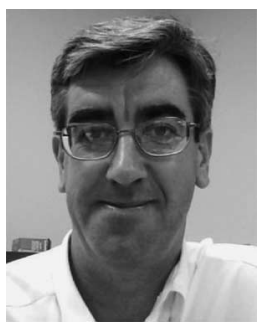

Stephen J. Pearton (F'01) received the Ph.D. degree in physics from the University of Tasmania, Hobart, Australia, in 1983.

$\mathrm{He}$ is currently a Distinguished Professor in Materials Science and Engineering at the University of Florida (UF), Gainesville. Prior to joining UF in 1994, he was a Member of Technical Staff at the AT\&T Bell Laboratories, Murray Hill, NJ. He has published more than 1200 journal papers and given more than 250 invited talks in international conferences.

Prof. Pearton is a Fellow of The Minerals, Metals, and Materials Society, American Vacuum Society, American Physical Society, and Electrochemical Society.

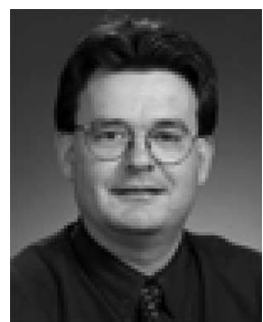

David P. Norton received the Ph.D. degree in electrical engineering from Louisiana State University, Baton Rouge, in 1989.

$\mathrm{He}$ is currently a Professor of Materials Science and Engineering at the University of Florida (UF), Gainesville. Prior to joining UF in 2000, he spent 11 years at the Oak Ridge National Laboratory. $\mathrm{He}$ has published more than 200 journal publications and organized many conferences for professional societies.

Prof. Norton is a Fellow of the American Vacuum Society.

Matt P. Ivill is a graduate student with the Department of Materials Science and Engineering, University of Florida, Gainesville. His dissertation work involves investigation of ferromagnetism in $\mathrm{ZnO}$ and related alloys.

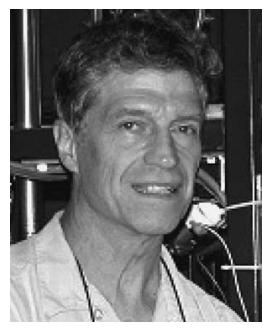

Art F. Hebard received the Ph.D. degree in physics from Stanford University, Stanford, CA, in 1972.

$\mathrm{He}$ is currently a Professor in the Department of Physics, University of Florida (UF), Gainesville. Prior to joining UF in 1996, he spent 23 years at the AT\&T Bell Laboratories as a Member of Technical Staff. In 1991, his paper in Nature on superconductivity in potassium-doped $C_{60}$ was the most frequently cited paper of the year.

Prof. Hebard is a Fellow of the American Physical Society and American Association for the Advancement of Science. He serves on the editorial board of several journals and is an Associate Editor of reviews of modern physics.

John M. Zavada received the Ph.D. degree in physics from Duke University, Durham, NC, in 1971.

He is currently a Contract Monitor in the Electronics Division, U.S. Army Research Office, Research Triangle Park, NC. He manages a large number of projects on optics, photonics, and spintronics, and has organized many conferences for professional societies.

Weimin M. Chen received the Ph.D. degree in physics from the University of California, Los Angeles, in 1988.

He is currently a Professor of Physics at Linköping University, Linköping, Sweden, and the Director of the Swedish Interdisciplinary Magnetic Resonance Center, Linköping University. His research interests include impurities and defects, semiconductor physics, spintronics, dilute nitrides, and SiC.

Irina A. Buyanova received the Ph.D. degree in physics from Moscow State University, Russia, in 1990.

$\mathrm{He}$ is currently an Associate Professor of Physics at Linköping University, Linköping, Sweden. Her research interests include impurities and defects, semiconductor physics, spintronics, and dilute nitrides. 